\title{
Editorial Preface: Why Cross-National Studies Between Japan and Sweden?
}

\author{
Thomas Taro Lennerfors $^{1} \cdot$ Kiyoshi Murata $^{2} \cdot$ Hiroshi Koga $^{3}$
}

Published online: 30 April 2021

(c) Springer Japan KK, part of Springer Nature 2021

For the last decades, people's lives, public and private organizations, and societies have been increasingly intertwined with developments in information and communication technologies (ICT). From the early beginnings of ICT, as is shown in the 2011 BBC documentary All Watched Over by Machines of Loving Grace, there were positive visions embedded in ICT that human beings would be able to relate to each other in an ethical way and lead environmentally sustainable lives. ICT could assist democracy, equal treatment, access to resources, and not the least it could help us plan for a resource-efficient society. Today, the view of ICT is more nuanced. ICT is seen as a perfectly malleable, in other words multi-purpose technology [3], which can be used to promote positive values (democracy, equal treatment etc.), as well as support less socially accepted values (crime, digital divide, environmental pollution). Thus, since the 1980s there is a lively debate about ICT development and usage, where ICT is assessed from an ethical perspective and where it is discussed how we can make more ethical ICT. A current debate concerns whether ICT should be as transparent as possible, in other words, promote the autonomy and decision-making capacities of the user, or whether it should nudge users into socially accepted behaviours. Furthermore, since the 2000s, peripheral questions about the environmental sustainability of ICT have become more central, since the energy consumption of ICT is significant and that the waste flow of ICT equipment is hazardous and growing. Most of the research within sustainable ICT is technical, while there are exceptions. The recent advancement of ICT centred on big data, Internet of

Hiroshi Koga

koga@res.kutc.kansai-u.ac.jp

Thomas Taro Lennerfors

lennerfors@gmail.com

Kiyoshi Murata

kmurata@meiji.ac.jp

1 Department of Civil and Industrial Engineering, Uppsala University, Uppsala, Sweden

2 Centre for Business Information Ethics and School of Commerce, Meiji University, Tokyo, Japan

3 Faculty of Informartics, Kansai University, Osaka, Japan 
Things, robotics and Artificial Intelligence has compelled us to reconsider the meaning of human existence, autonomy, freedom and dignity. $[8,9]$ has raised an alarm over the advent of surveillance capitalism, an emergent, but invisible, logic of accumulation, of which big data is both a condition and an expression, and cautioned about its posing serious threat to freedom and democracy.

The project of which this special issue is a part aims at investigating and proposing policies for developing and using information and communication technology (ICT) which contribute to sustainability and promote morality and ethics, through cross-cultural research between Japan and Sweden. The aim has two aspects. One is (a) to analyse the nature of ethical, social and environmental issues and problems which possibly or actually arise with the development and use of ICT, and to propose policies to proactively or reactively cope with them. The other is (b) to propose policies to resolve existing ethical, social and environmental problems using ICT. In the study, "sustainability" does not necessarily mean environmental sustainability. The study deals also with sustainability related to society, economy, culture and human nature. Morality and ethics in this study are associated not only with preserving well-known values such as human dignity, autonomy, freedom, human rights and democracy, but with revising existing values and proposing new values.

Japan and Sweden have a lot in common. Both of the countries support democracy and capitalism under the political system of constitutional monarchy, and are advanced countries in ICT. In these countries more than $90 \%$ Internet penetration rates [93.8\% in Japan in June 2020 and 96.4\% in Sweden in June 2019; Internet World Stats (https://www.internetworldstats.com/stats.htm; accessed on 5 October 2020)] are achieved, and there are global ICT companies based in the countries such as Sony and Ericsson. On the other hand, in terms of social characteristics and cultural traits, as well as of the historical backgrounds of them, Sweden marks a sharp contrast with Japan. Swedish society is multiracial and multicultural. Ethnic, religious, cultural and gender diversity is respected for, although the recent increase in the number of refugees have been considered as a social problem. Complete gender equality is legislated so that, for example, the equal burden of childcare and housework between both partners is ensured. A high-level consciousness of the conservation of the natural environment as well as the protection of human rights is shared among Swedish citizens. The systems of high tax burden and generous social-welfare have socially been accepted. The national personal identification number system, which started in 1947, has been computerised, and the personal identity numbers (personnummer) are used in various aspects of citizens' personal and social life without bringing their feelings of hesitation. A full-scale cashless society will soon be realised in the country (Alderman 2018).

Contrary to these, Japanese society allegedly has an ethnically homogeneous nature, and many Japanese people believe that Japan is a monolingual and monocultural nation, where microaggression against ethnic minorities and the socially vulnerable is not uncommon. There is strong social resistance to the immigration intake-especially the intake of refugees-whereas the number of foreign workers is increasing due to a worker shortage caused by the falling birth-rate and the aging population. Japanese society has still been androcentric. Even though the Basic Act for Gender-Equal Society was enforced in 1999 and the government emphasises the 
importance and necessity of utilising female workers in various areas of work, the traditional stereotyped perception for gender roles has been maintained. The rights of women as well as children are not sufficiently emphasised in Japanese society, as shown in the former health minister's statement that women are child-giving machines [2]. Economic growth is often prioritised over conservation of the natural environment by Japanese policymakers. Freedom of the press in Japan receives a far lower evaluation than one in Sweden, 2020 World Press Freedom Index of Japan was 28.86 (66th place out of 180 countries) whereas one of Sweden was 9.25 (4th place) [5]. After the long series of failures of setting up national personal identification number systems since the end of 1960s due to public backlash, the operation of a resident number system called the My Number System was launched in January 2016 in Japan. However, only three kinds of ways of using the system are legitimatised: taxation, social security, and individual discernment at the time of serious disaster. Cashless payments including mobile and credit card payments are not necessarily widespread in Japan. Actually, 21.4\% of Japanese household expenditures were paid via cashless mode in 2017, whereas $47.4 \%$ in Sweden [4].

Needless to say, we have to avoid being fixed on stereotypical images or understandings of Japanese and Swedish cultures. For example, the widely believed idea of Japanese collectivism or groupism has been criticised by many researchers [1, $6,7]$. The pandemic of COVID-19 revealed that Japan is not necessarily a digitally advanced country. The widespread use of paper-based documents to which seals are put for authentication is still commonplace at Japanese organisations in both the public and private sectors and has become an obstacle to teleworking.

The major purpose of this study of which this special issue is a part, as described above, is to propose concrete policies for developing and using ICT which contribute to sustainability and promote ethics. To achieve the purpose in today's ICT-dependent globalised world, we need to avoid easily slipping into ethnocentric mentality and to attempt to formulate "globally acceptable, and locally effective" policies. In this respect, setting up a cross-cultural or cross-national research scheme is necessary and effectual in this study. In addition, given that (a) leading researches on sustainability and information ethics have mainly been conducted in ICT advanced countries in the West and in Japan amongst non-Western countries, that (b) Japanese society has been Americanised to a certain extent after WWII while maintaining its unique cultural characteristics which cannot easily be understood through the lens of Sinosphere or the East Asia cultural zone and that (c) Swedish culture and values cannot lightly be lumped into the same group as Western ones, a cross-national study between Japan and Sweden dealing with those topics of research is one of the most interesting and promising initiatives in the study fields of sustainability and information ethics.

\section{References}

1. Funabiki, T. (2020). Nihonjinron reconsidered. Kodansha. (in Japanese). 
2. McCurry, J. (2007). "Japanese minister wants 'birth-giving machines', aka women, to have more babies." The Guardian, 29 Jan. https://www.theguardian.com/world/2007/jan/29/japan.justinmccu rry (accessed on 5 October 2020)

3. Moor, J. H. (1985). What is computer ethics? Metaphilosophy, 16(4), 266-275.

4. Payments Japan Association. (2020). Cashless Roadmap 2020. (in Japanese) https://www.payme ntsjapan.or.jp/wordpress/wp-content/uploads/2020/06/roadmap2020.pdf (Accessed on 5 October 2020)

5. Reporters without Borders. (2020). 2020 World Press Freedom Index. https://rsf.org/en/ranking\# (Accessed on 5 October 2020)

6. Takano, Y. (2008). The illusion of collectivism: the misconception in Nihonjinron and its origins. Shinyosha. (in Japanese).

7. Yamagishi, T. (2010). Wrong assumptions about Japanese culture: the illusion of collectivist culture. Chikumashobo. (in Japanese).

8. Zuboff, S. (2015). Big other: surveillance capitalism and the prospects of an information civilization. Journal of Information Technology, 30, 75-89. https://doi.org/10.1057/jit.2015.5

9. Zuboff, S. (2019). The age of surveillance capitalism: the fight for a human future at the new frontier of power. Profile Books.

Publisher's Note Springer Nature remains neutral with regard to jurisdictional claims in published maps and institutional affiliations. 